\title{
Un debate metodológico entre dos aproximaciones al estudio de caso: Caso de conciencia frente a estudio de caso histórico-humanista
}

\author{
Antonio Fernández Cano, Teresa Lara Moreno, \\ Juan de Dios Melgarejo Jaldo y Ángel Bueno Sánchez
}

Arbor CLXXI, 675 (Marzo), 513-532 pp.

Este estudio considera dos aproximaciones a un método de investigación tan complejo como el estudio de caso. Por un lado, el antiguo y seminal enfoque del caso de conciencia, se considera con profundidad. Por otro, también desarrolla conceptual y metodológicamente una de las diversas acepciones actuales al estudio de caso, la histórico-humanista según propuso Caro Baroja. El objetivo central de este trabajo podría ser presentar la aproximación histórico-humanista como contraste con su alter ego, el pretérito caso de conciencia, exponiendo coincidencias y diferencias entre ambas.

\section{Una consideración preliminar}

No es nuestro propósito hacer declaraciones tajantes, ni llevar la discusión a un fin y, menos aún, declarar verdades infalibles. Este artículo no es un resumen legal, ni tampoco una exégesis bíblica. Abrigamos la esperanza de que tras la lectura de este texto, el investigador que opere con estudio de casos, comprenda que tal método tiene un rico antece- 


\section{Antonio Fernández Cano, Teresa Lara Moreno...}

dente como fue el caso de conciencia y cuya influencia en el campo educativo fue notable, especialmente en el estudio del desarrollo de la Educación Moral (véase Fernández Cano, en este número). Un supuesto adicional se asume de modo optimista: si sabemos dónde hemos empezado, seremos capaces de tener una mejor perspectiva de hacía dónde queremos ir.

No estamos abogando por promover que la aproximación del caso de conciencia (desde ahora abreviadamente CC) sea aplicada para resolver cuestiones éticas. En su momento, el CC tuvo que hacer frente a todo un espectro de investigación que el tiempo se encargó de difuminar y, supuso, entonces, un notable apoyo para el despliegue de las tareas educativas.

\section{Estudio de caso: Un término ampliamente usado}

El uso del estudio de caso (desde ahora, abreviadamente, EC) como método de investigación en Ciencias Sociales y, por consiguiente, en Ciencias de la Educación se incrementa y expande quizás como una respuesta a las promesas no cumplidas de otras formas «más científicas» de métodos de investigación educativa. Cualquier estudio metodológicamente atrevido o difícil de adscribir a un método predeterminado, pretende estar realizado a través de EC, como si aquel tomase la validez del término. Es evidente que existe una plétora de estudios, en las más diversas disciplinas que precipitan en el campo de la educación, denominados a la ligera e infundadamente como ECs.

En Bromley (1986, pp. 7-10) y Stake (1988, pp. 253-278), el lector podrá encontrar una lista de términos sobre la idea de EC. Son múltiples las variantes aceptadas y podrían incluir a: estudio etnográfico, informe de caso (case-report), caso legal o aproximación cuasijudicial, historia de vida, relato de vida, constructo intelectual, informe psicodiagnóstico, estudio de caso de una tentativa o aproximación modus operandi ${ }^{1}$, diseños $\mathrm{N}=1$ (o diseños de sujeto único o de línea base) y diseño de serie temporales de grupo único. Cada una de estas acepciones del EC obedecen a la disciplina en la que el EC opera y se enraízan en ella como método de indagación propio.

Ante tanta diversidad de acepciones, pudiera pensarse que el síndrome del lecho de Procrustes ${ }^{2}$ (Howe y Eisenhart, 1990) está inexorablemente presente cuando se valora una investigación realizada mediante EC. Y dado, además, que algunos consideran y utilizan al EC tan ligera 
y superficialmente, sería necesario, entonces, establecer ciertos límites metodológicos a su uso.

A pesar de este polimorfismo que pareciera ser un síntoma de debilidad, el EC es un método de investigación bien fundamentado y actual. La Asociación Mundial para la Investigación y Aplicación del Método de Casos (WACRA: World Association for Case method Research and Application) es un exponente de su uso actual con sus conferencias internacionales anuales (Klein, 2000). Pero sobre todo, el EC tiene una larga tradición reavivada en años recientes que recorre la columna vertebral de la historia del conocimiento.

\subsection{Falsas concepciones sobre el estudio de caso}

Es posible localizar en la literatura sobre EC y en las creencias de los investigadores una serie de falsas concepciones sobre este método, entre las cuales podríamos incluir las siguientes:

Método aislado. El EC es un método básico de indagación científica, quizás el básico, pero no excluye otros métodos diseñados para tratar con diferentes tipos de problemas (Toulmin, Rieke y Janik, 1979).

De hecho, y en búsqueda de la deseada complementariedad metodológica, el EC podría usarse con una multiplicidad de métodos disponibles para obtener hallazgos creíbles e, incluso, causaciones consistentes.

Comprensión raquitica. El EC no sólo permite alcanzar intuiciones fundadas, sino que también tiene la fuerza para confirmar o refutar una ley o principio derivados de una teoría. Bromley (1986, p. 289) expone que un solo caso pudiera ser convincente e incluso conclusivo. $\mathrm{O}$ sea, tal como la lógica deductiva dicta, una simple refutación es más efectiva para falsar una teoría que múltiples confirmaciones (Platt, 1964).

Esta visión, por la simplicidad, ha determinado que los investigadores cuantitativos consideren al EC como un medio para generar hipótesis, cuando usan casos típicos, o considerar a los «islotes» (outliers) como caso atípicos que no verifican una hipótesis globalmente aceptada. Sin embargo, los investigadores cualitativos han ido más allá, hasta el punto de considerar al EC como generador inductivo de teoría fundamentada (Glaser y Strauss, 1967).

Ausencia de rigor disciplinado. El EC tiene reglas de evidencia y fuentes de error, como cualquier otro método de investigación, en sus cuatro fases procedimentales: enfoque del problema, recogida de datos, análisis de datos y discusión de hallazgos relativos a relaciones encontradas, soluciones propuestas y/o decisiones tomadas. Antes de iniciar un 
EC, sería apropiado tener in mente por anticipado los cánones de evidencia y los supuestos previos, para poder verificarlos fielmente durante la investigación. Estos cánones y supuestos atañen a la validez, a la fiabilidad y a aspectos éticos de la investigación, y debieran ser continuamente evaluados y expuestos en el informe del caso.

Todo EC puede y debiera ser riguroso, aunque el control de las cuestiones metodológicas es más responsabilidad directa y continua del investigador, y menos del diseño de la investigación propuesto de antemano.

Bajo empirismo. El EC opera con hechos empíricos de muy distinta naturaleza y hechos concretos procedentes de múltiples fuentes. Se requiere, por tanto, la selección, por cualquier procedimiento muestral, de un conglomerado específico de observaciones naturales (o cualquier otro dato empírico), a partir de una población sensible de observaciones admisibles.

Generalización imposible. Un EC no pretende desarrollar generalización alguna; aunque sus resultados tienden a ser generalizables en el grado en que el lector pueda encontrar similitudes entre el caso informado y el caso propio, el vivenciado por el lector. Además, el desarrollo de un EC en escenarios múltiples pudiera ser usado con función generalizadora. Pero, tal como Campbell (1975) se refería a esta cuestión, ¿cuántos grados (escenarios) de libertad necesitamos para generalizar? Sturman (1997) da esta respuesta:

... es necesario asegurarse de que los rasgos relevantes de un caso están documentados, tal que una nueva situación pueda iluminarse por una comprensión muy completa del caso conocido (p. 63).

Estructura inadvertida. Un caso no se estudia al margen de su estructura conceptual. Se delinea en una serie de contexturas: física (de tiempo, lugar y gentes), sistémica (anidado o cruzado en el campo) e ideológica (girando alrededor de una amplia constelación de normas, valores y creencias). La definición de un EC como un sistema acotado (Stake, 1988) es, en verdad, precisa y apela a una cierta conceptualización de la unidad o totalidad de un sistema con cierto tipo de limites o fronteras; caso en el que se encuentra algo valioso, «agua dulce» dice el propio Stake.

Sesgo procualitativo. El EC opera en diversos programas epistemológicos. En el programa positivista, adopta una tendencia reduccionistaunitarista a la recherche de las características primarias, manifiestas y elementales del caso, tal como puede inferirse del libro de Durkheim, Las formas elementales de la vida religiosa (1982). En el programa interpre- 
tativo, el EC es pluralista, ya que escudriña cualidades complejas, contextuales, secundarias, dispersas y no manifiestas, aunque obviamente no son menos básicas (al respecto, véase Gutiérrez, Pozo y Fernández Cano, en este número).

\section{El estudio de caso histórico-humanista: ¿Por qué no otra aproximación?}

Disponemos de libros funcionales y útiles que describen el EC como un método general de investigación (i. e. Bromley, 1986; Coller, 2000; Merriam, 1988; López-Barajas y Montoya, 1995; Ragin y Becker, 1992; Stake, 1988; Yin, 1989). Además, hay muchos más trabajos de investigación y de corte metodológico sobre EC de los que a primera vista pudiera parecernos. Así, si se realiza una búsqueda bibliográfica a través de las diversas bases de datos de ciencias sociales (ERIC, SSCI, PsychInfo,...), usando los descriptores Case Study and Research Methodology, propios de cualquier tesauro completo, encontraremos que esa búsqueda arroja bastantes referencias. Un ejemplo palmario y próximo de ello puede localizarse en Delgado López-Cózar y Fernández Cano, en este número.

Aquí, se considera otra acepción más al EC, tratando de instrumentar un nuevo significado del EC que resuma su desarrollo histórico en la tradición metodológica hispana. Julio Caro Baroja (1985, pp. 29-41), el maestro de la Etnohistoria española, ofrece esa nueva cualificación del EC tal como fue utilizado por él mismo. Ese nuevo significado del EC puede encontrarse en el prefacio de su magistral trabajo Las formas complejas de la vida religiosa. Siglos XVI y XVII, el cual mereciera ser tenido más en cuenta dentro del campo educativo. Las facetas metodológicas de esta aproximación al EC se delinean brevemente a continuación:

Estudio descriptivo. Un EC creíble es una descripción detallada, una pintura de una persona, grupo, institución, fenómeno o experiencia seguida de juicios holísticos no maniqueos. El investigador debe encontrar un equilibrio entre la subjetividad, la cual puede conducir a una frívola exaltación de los rasgos locales y primitivos (i.e. el mito del buen salvaje en el naturalismo de Rousseau), y la objetividad, la cual podría llevar a un esquematismo desencarnado. Incluso en investigación evaluativa, todo EC acaba habitualmente con un juicio sin sesgo pretendido.

Estudio interpretativo. El EC está abierto a variaciones de contenido y a diversas interpretaciones de significado. Esto implica una ausencia total de casos típicos que podrían conducir a interpretaciones maxima- 
listas. Las teorías generales y las creencias personales no son adecuadas desde el principio. La evidencia debe presentarse completamente, incluso con sus múltiples desacuerdos. No es necesario coordinar las ideas que aparecen como contrarias mediante razonamientos forzados. La evidencia no será reducida a reglas generales si no estamos seguros de poder extraer una verdad oculta. Analizar es correcto pero, una síntesis inconsistente o inverosímil, no lo es. Caro Baroja (1981) reclama incluso:

Reemplazar la palabra «teoría» por «opinión» [comillas en el original] podría ser más apropiado especialmente cuando tales «opiniones» adolecen de un verdadero soporte "teórico»... Emitir una opinión sobre un caso es pertinente y necesario pero nombrar esa opinión con el pomposo nombre de «teoría» hace al investigador aparecer como un falso astrónomo. Y más si esta conducta se adopta con demasiado frecuencia (pp. 456-457).

El EC juicioso es disciplinado pero a menudo subjetivo y la inducción a lo general no es requerible, incluso si es un pensamiento común. Con la búsqueda de la comprensión de lo particular, un EC está bien servido.

Un caso debiera ser interpretado con objetividad, distanciando nuestra mente de los puntos de vista personales, experimentando la posibilidad de compartir la experiencia de otros, tomando la posición de ellos. La fuerza de un caso debe ser tal que nos fuerce a la inducción, avanzando desde lo particular a lo general a través de la personalización.

Regularidad inductiva. Los casos son patrones inductivos tal como un relato, acorde con lo que en términos teatrales se llama dramatis personae, en el estilo de la Nueva Comedia, la ética, de Menandro, en la cual aparecen caracteres y no individuos predeterminados. Caracteres tales como el tirano de Herodoto, el oligarca de Platón, los arquetipos descritos en el Pseudomantis de Luciano o en Los caracteres de Teofrasto. El caso es un espejo de la vida que refleja caracteres y fenómenos: nuevos, viejos y siempre cambiantes.

Arte retórico. El estudio de un caso es un arte que usa una retórica, la cual sirve para presentar el informe final del modo más claro posible (Aristóteles, Retórica, I(3), II). De aquí que un EC sea un arte que trata de discernir los medios más adecuados para convencer. La cuestión no es sólo examinar las formas de los entimemas sino el contenido argumental, las pruebas y/o la explicación que éste aporta.

Modelo flexible. Un caso admite un modelo previo o puede ser una novedad sin antecedentes, aunque debiéramos encontrar medios para interpretar o contrastar el caso antiguo con el nuevo. Por ejemplo, a través de analogías o metáforas paramitológicas como una explicación de cierto fenómeno actual (i.e. el mito de Sísifo ${ }^{3}$ al inicio de cada curso escolar). 
Un debate metodológico entre dos aproximaciones al...

Pero, ¿hay casos nuevos que puedan ligarse a un arquetipo antiguo? ¿no hay nada nuevo bajo el sol de las ciencias humanas? Este es un viejo dilema. Una respuesta a esta crítica cuestión fue dada por uno de los más sutiles casuistas ${ }^{4}$ españoles, Rodrigo de Arriaga (1962), cuando observó:

Nosotros tenemos la ventaja sobre los antiguos de tener la riqueza de la experiencia. Muchas cosas se les presentaron a ellos y aún ellas siguieron ocultas. ¿PPor qué no es lícito para nosotros extraer nuevas consecuencias, mostrar que a veces algunas conclusiones no son correctas, ponderar sus razones y aún encontrarlas faltas? (p. 203).

Incluso cuando "se piensa sobre un caso particular», el esquema, los modelos, las categorías y las estructuras están todas fuera de lugar, son algo déjà vu, déjà connu. Las recurrencias y las coherencias inconscientes son los elementos más significativos para su estudio.

Preocupación por el matiz. Un caso admite sutiles círculos y grados de complejidad con todos los rasgos y matices que podamos percibir. La habilidad para descubrir estos matices es fundamental en un EC, incluso cuando sólo podamos usar datos de la experiencia o de la intuición personal.

Evidencia cogitante. Las fuentes de evidencia en el EC son múltiples y la critica a su validez interna y externa debiera ser completa; aunque tales críticas no debieran nunca hacernos olvidar que la cuestión relevante es pensar sobre el caso. La investigación con EC es una empresa ecléctica, una aproximación comprehensiva al conocimiento.

Procedimiento abierto. Aparte de todo lo dicho anteriormente, podría añadirse que el procedimiento metodológico para realizar un EC no es algo constreñido, ni mecánico.

Se entra en el caso llevado por una curiosidad inicial; la búsqueda y evaluación de las fuentes ha de llevarse a cabo al mismo tiempo. A continuación, impelido por una fuerte comezón, inicias la redacción del informe reuniendo piezas, mas no necesariamente empezando desde un principio. El siguiente retazo de un consejo, similar a otro ofrecido por Carr (1967), pudiera sernos útil:

Indagar e informar un EC van simultáneamente. La investigación se orienta, se dirige y se hace productiva a través del informe: cuanto más informo, más sé lo que estoy buscando. Al tratar de informar, se comprende mejor el significado y la relevancia de lo que voy encontrando (pp. 32-33). 


\section{Una antigua acepción del estudio de caso: El caso de conciencia}

En otra parte de este monográfico (véase Fernández Cano), se puede obtener cierta comprensión sobre este vetusto método del CC, en un ensayo histórico-metodológico a la búsqueda de antecedentes del EC. Casuistas fueron aquellos que estudiaron y trabajaron con CCs; y su nómina, aún en estudios contemporáneos, es bien extensa: Attisani, 1957; Bujanda, 1960; Dublanchy, 1932; Ferreres, 1926; Genicot, 1901; Gury, 1865; Hilgenreiner, 1933; Lumbreras, 1960.

Dublanchy (1932) da la siguiente definición de CC:

Un hecho bien definido, ficticio o real (un hecho cuestionable en sí mismo), tanto social como individual, mediante el cual se decide de acuerdo a las normas de ciencia [aquí, en este contexto, evidentemente, la ciencia teológica] la existencia o no de ciertas obligaciones morales (col. 1815).

Glosando la anterior definición, podemos decir:

- El CC se centra en un hecho concreto; es decir, todo hecho inserto en un CC debiera estar acotado considerando: un objeto específico (el fin o moralidad perseguida), circunstancias objetivas que pudieran modificar el objeto específico (circunstancias personales ${ }^{5}$ tales como medios, cantidad, lugar, tiempo u otras) y circunstancias subjetivas de amonestación (total, imperfecta o nula) y/o consentimiento (informado, parcial o nulo).

- El CC es real o ficticio. Un CC real pretende ser una aproximación directa para regular la conducta previa a una acción, reasegurar la conciencia, aconsejar o iluminar a otra persona sobre un cierto evento. El CC ficticio puede ser un caso real, en el que ciertas particularidades se han omitido por prudencia, o también un caso totalmente artificial, metódicamente combinado con el fin de ejercitar el juicio sobre aplicaciones morales, particularmente aquéllas que presentan serias dificultades debido a la diversidad de circunstancias.

- El CC es individual o social. Puede referirse a obligaciones personales (con Dios, consigo mismo o con otros) o responsabilidades propias de un grupo (con el Estado, con otro grupo, derechos mutuos, etc.). El CC conlleva una gran preocupación por el ser humano en la línea del espíritu del mejor humanismo, el renacentista. Cuando la Casuística Moral encontró su propia senda, no pudo dejar al margen la vida y acciones de hombres y mujeres. 
Un debate metodológico entre dos aproximaciones al...

- El CC se evalúa moralmente. Una vez que se juzga un CC, se toma una decisión de acuerdo a las conclusiones normativas de la ciencia teológica; es decir, la decisión se subordina unilateralmente a la ley natural o a principios revelados. La decisión atañe a la existencia o no de obligaciones morales. Resolver un CC implica elaborar una declaración sobre su legalidad o sobre el carácter de la falta (venial/menor o grave/mayor). En otras palabras: el caso se evalúa por medio de un juicio global y por una valoración sinóptica, ambos moralmente consistentes.

Dos fueron las funciones principales del CC, como:

- Método didáctico, denominado por lo general método de casos en diversas disciplinas (Moore, 1956). Los orígenes del método de casos son bastantes antiguos (ver López, 1942; Moore, 1990). Se puede encontrar excelente información sobre este método de caso en Andrés (1980), Mucchielli (1970), Pérez Serrano (1994) o Ramírez (1972), siguiendo las orientaciones jesuíticas entremezcladas con propuestas pedagógicas no directivas. McNair (1959) ofrece una orientación similar para el aprendizaje de las ciencias legales en la Harvard Business School.

- Método de investigación. En este sentido será considerado y usado a lo largo de este ensayo. Una caracterización exhaustiva del CC como método de indagación en Teología Moral, en casuística, se localiza en los trabajos de Moore $(1956,1990)$

\subsection{Fuentes del caso de conciencia}

En la instrucción de CCs, los casuístas usaron cuatro fuentes básicas:

- Literatura. La información para CCs se obtenía de escritores antiguos, particularmente de aquéllos mejor conocidos, y después adaptados a las nuevas circunstancias. La amplia experiencia acumulada a través de siglos se exhibe en los CCs contenidos en sumas y prontuarios. Un ejemplo extremo pudieran ser los casos incluidos en la Suma de Diana ${ }^{6}$, que llegan a abrumar a causa de las numerosas citaciones a autoridades. Cuando se lee este libro, es posible encontrar más de una página de citaciones por caso. Pronto, el lector comprueba que no es necesario citar a tantas autoridades, y que lo mejor que haría sería pensar por sí mismo.

- Entrevistas de tres tipos. Por un lado, los informes confesionales, indicando las circunstancias objetivas y subjetivas de la conducta del penitente, tal como éste se lo cuenta al confesor. Por otro lado, 
las personas demandan consejo para resolver problemas personales de conciencia, entonces el casuista actúa con ellas como un consejero u orientador. Por último, el casuista consulta a otros colegas.

- Observación. Una visión de la realidad inmediata de acuerdo con la aproximación «el conocimiento del mundo» propuesta por la Escuela Teológica Legal de Salamanca (con autores como Vitoria, Soto, Cano o Suárez) y explicada en sus tratados De Iustitia et Iure [Sobre la ley y la justicia].

- Discusión. Un CC lograba enriquecerse cuando se implementaba mediante enseñanza discursiva. En colegios, e incluso en casa de la Compañía de Jesús, la moral práctica se enseñaba como cualquier otra materia escolar (Casus Conscientiae) a clérigos y laicos.

Para resumir, las fuentes del CC eran las clásicas: lectura, atención, indagación y observación. Gury (1894) expresaba esta pluralidad de fuentes en la obtención de CCs diciendo:

He escrito acerca de muchos casos reales que he ido reuniendo, y que he conocido durante los muchos años en que estuve conduciendo almas. Y también de muchos otros casos, que me fueron expuestos por venerables sacerdotes, en busca de una causa (p. vi).

\subsection{Informe del caso de conciencia}

Los CCs se compilaban en manuales denominados sumas (ver Fernández Cano en este número). En las sumas históricas, era usual informar del CC utilizando el siguiente formato: descripción ${ }^{7}$, cuestiones sobre el caso y solución de las cuestiones, contestadas de una manera definitiva (afirmativa o negativamente) o de un modo condicional o probable. La solución provisional debía estar inmediatamente justificada en base a los principios morales afectados. Esta justificación se documentaba después en referencias normativas extraídas de las siguientes fuentes: doctrina positiva, doctrina especulativa, textos legales autorizados y la propia argumentación personal. En esta última fuente, el propio casuísta hacía uso de su razonamiento teológico, especialmente de la técnica interrogativa a cuestiones contestadas con SÍ-NO.

Es obvio que los dilemas morales abiertos propuestos por Kohlberg (1981) guardan un formato bastante similar al del CC. Ambos usan situaciones concretas, que presentan un problema de decisión moral (a nivel de conciencia en el CC y a nivel de conflicto de valores en el dilema), y, para el análisis y discusión de ambos, es necesario aplicar principios 
Un debate metodológico entre dos aproximaciones al...

morales inherentes (teológicos en el CC o de la autonomía personal en el dilema).

Tantos en los viejos CCs, como en los más actuales dilemas alternativos, parece evidente que, ni los principios de la sindéresis (el sabio discernir), ni la derivación inmediata de la ley natural, o la aplicación de teorías sociales, permiten emitir una norma universal que pueda resolver completamente el conflicto manifiesto. Estamos enfrentados con aquellos casos cuyo proceso de resolución no es sencillo y que siempre proporcionan esa agitación tan propia de la vida real.

\subsection{Finalidad del caso de conciencia}

El CC cumplió varios fines, a saber:

- Profundizar en el conocimiento moral, el cual en su aplicación correcta hace posible analizar con más detalle los matices y advertencias que pudieran tomarse en consideración. El CC permitió a la Moral avanzar desde una dimensión puramente especulativa a una dimensión aplicada. Leyendo hoy día aquellas colecciones de CCs, particularmente los más normativos, aparecen al par una exuberante y creíble flora de descripciones ajustadas.

El estudio y desarrollo de CCs derivó, en lo que Dublanchy (1932) describió como casuística científica, al considerar el supuesto capital de que, sólo el conocimiento especulativo y positivo de los principios morales (naturales o revelados), no era suficiente para orientar las acciones humanas. Es esencial contrastar aquellos principios generales, con una rica multiplicidad de casos precisos, para discernir la correcta obligación de la conciencia.

- Actuar como medio de guía espiritual. Para personas con necesidad de orientación, el CC les aporta y reconforta con verdaderos consejos. Se asume que la conciencia personal no es, a veces, suficiente para juzgar la moralidad de las acciones de un modo espontáneo y autónomo, sobre todo, cuando circunstancias complejas relativas a la acción obstaculizan una correcta aplicación de los principios generales o cuando hay conflicto de valores. Como alternativa, un experto (el casuista) puede estudiar e iluminar la cuestión o punto en disputa emitiendo un veredicto de probabilidad.

- Enseñar Moral a las personas. Otro fin del CC fue la educación moral de los sujetos, quiénes, oyendo las razones de los expertos pueden asimilarlas e internalizarlas para una posterior aplicación a situaciones similares. Consecuentemente, el sujeto ganaría comprensión al presentársele nuevas cuestiones. 
Sin embargo, una ambición de los estudios sobre CC, cual era obtener un tipo de penitencia estandarizada a modo de norma general, no se logró. Intentos de mejora fueron hechos sin mucho éxito, en el sentido de impartir la misma penitencia para el mismo pecado debido a la arbitraria asignación de tasas por diferentes confesores. El éxito, en este sentido, habría significado el fin del casuismo.

- Desarrollar un método para la formación de expertos: predicadores, confesores y maestros, no sólo clérigos. Cuando se consulta cualquier libro sobre CCs resalta a primera vista una fuerte estructuración; los temas, basados en la realidad individual e inmediata y los casos afines, se disponen de acuerdo a situaciones cotidianas y no depende la secuencia expositoria de principio moral alguno. En conclusión, estos libros están estructurados con un orden altamente didáctico.

- Ganar conocimiento práctico sobre cómo elaborar decisiones probabilistas cuando nos enfrentamos con principios y teorías generales (teológicas, aquí), por un lado, y con las veleidades de la vida real, por otro.

\section{Coincidencias entre caso de conciencia y estudio de caso histórico humanista}

No es azaroso enfatizar una serie de coincidencias entre ambas corrientes metodológicas que, a primera vista, pueden parecer histórica y epistemológicamente tan divergentes; aunque, las diferencias también son manifiestas, como veremos. Algunas de estas coincidencias pudieran ser:

- Comparten la cualidad eminentemente práctica del conocimiento. Ambas tienen la convicción de que la teoría hecha de principios generales, per se demuestra ser insuficiente para la comprensión de la realidad. $\mathrm{CC}$ se define generalmente como método en contacto con actos humanos. EC desconfía de la capacidad de la teoría general para explicar un hecho preciso.

- Comparten el requisito de indagar lo intrincado de la realidad social y humana. El CC no habría sido necesario para la Teología Moral si la aplicación de principios morales hubiese sido hecha por una simple transposición del principio general al hecho particular. Pero ante la complejidad, dada por las circunstancias ${ }^{8}$ objetivas y subjetivas, en las que el hecho se enmarca, se demanda un estudio completo para iluminar la licitud probable del hecho, así como ayudar a la conciencia personal. Por 


\section{Un debate metodológico entre dos aproximaciones al...}

otro lado, las variantes más cualitativas de EC insisten en el descubrimiento de los significados particulares, que un acto adquiere, si sus adherencias contextuales son tenidas en cuenta.

El tener que adaptarse a circunstancias concretas hizo que los casuistas añadieran no sólo un corpus teológico y legal, para obtener una solución al caso propuesto, sino que tuviesen que tener en cuenta circunstancias objetivas de tiempo y lugar (sobre todo los usos y costumbres locales).

- Apoyados en la singularidad de un caso concreto. No hay dos casos iguales excepto para el novato no adiestrado que los percibe, el cual no es capaz de discernir matices y sutilezas. Es esa singularidad la que permite al EC focalizarse en un problema preciso y estudiarlo completamente. Por ello, ambos son también restrictivos en su espectro y profundamente focalizados; es decir, son sistemas conceptuales acotados.

- Aceptan la utilidad del conocimiento probable y, por tanto, la falibilidad de ese conocimiento probable. La certitud absoluta no es posible en la interpretación de un hecho moral. La solución probable se acepta como apoyo suficiente para determinar la licitud de la acción. El probabilismo estaba asociado al proceso de toma de decisiones, ya que cuando se duda sobre la ilicitud de una acción específica, enfrentados a una duda real (iuris vel facti) [factual o real], se puede lícitamente llegar a un juicio probable al margen de su naturaleza. En EC, la verdad completa está fuera del alcance e incluso no se considera posible alcanzarla. Comprender un EC es siempre una aproximación al «revelado» del funcionamiento de las estructuras de significados y a la formulación de una conclusión objetiva (probable) derivada de un argumento reflexionado, tras usar la mejor evidencia disponible.

- Preocupación por la hermenéutica, por las posibilidades de interpretación. El término hermenéutica se refiere a la tarea de traducir, interpretar y comunicar algo, que es incomprensible, ya que está escrito en un lenguaje extraño hecho de signos y símbolos, aunque tal declaración pudiera estar en el lenguaje de los dioses.

La posición filosófica subyacente en la investigación actual por EC ha sido tomada de la tradición aristotélica (en Ética a Nicómaco) y expresada por teóricos como Gadamer (1977). La distinción entre ciencias teóricas, productivas y prácticas, cada una con su forma distintiva de teorización (episteme, poitiké y praxis, respectivamente) y sus reconocidas normas de realización (theoría, techne y phrónesis, respectivamente), pusieron a esta última (phrónesis) en el campo del saber práctico: es el ingenio (ingenium) del juzgador el que aporta orientación e iluminación cognoscitiva para la praxis. 
Gadamer (1977) relaciona el método hermenéutico con la tradición metodológica en ciencias histórico-filológicas, teología y jurisprudencia. La comprensión judicial de la ley conlleva aplicarla correctamente y no aplicarla arbitrariamente. En otras palabras, esa aplicación se basa en una interpretación apropiada, lo cual implica que, cierta comprensión precisa, medie entre la concepción histórica y la vigente. La distancia, entre la posibilidad de generalizar la ley y la situación legal suscitada por cada caso, es por sí misma inacabable. Entonces, la tarea de la hermenéutica legal podría ser analógicamente similar a los desarrollos de la tradición casuísta.

La crítica histórica más fuerte contra $\mathrm{CC}$ fue que, ya que claramente se apoyaba la posibilidad de interpretación, podía caer en el laxismo, alejándose peligrosamente de la autoridad y de la tradición. En este mismo sentido, la conciencia hermenéutica también cuestiona ambas. Además, cuando el casuista persigue conocimiento práctico para tratar con una situación precisa, tiene que ponderar una variedad ilimitada de circunstancias. Esa aproximación exigía la prudencia y astucia de la odiséica phrónesis. Tanto el CC como el EC comparten los tres momentos hermenéuticos clásicos en la obtención de conocimiento: subtilitas intelligendi (comprensión), subtilitas explicandis (interpretación) y subtilitas applicandi (aplicación) -ver Gadamer, 1977, pp. 378-379.

- Comparten el objetivo de influir sobre las personas en su vida cotidiana. Ya Pascal (1966), en su VII. ${ }^{a}$ Carta Provincial, acusaba a la casuística de ansias de dirigir la intención, de acuerdo con normas laxas, no adecuadamente fundamentadas. EC explica e ilumina a los individuos sobre el significado de sus acciones, haciendo posible cambios prácticos que afectan al modo en que los individuos se ven a sí mismo y a sus respectivas situaciones personales.

Por otro lado, el fin último de las ciencias educativas, en el sentido más positivo del término, ¿es dirigir la acción, o no? En su significado más práctico, la educación está plena de normatividad, es normativa o no es nada.

- Hacen uso de los mismos instrumentos metodológicos para la recogida de datos. Instrumentos como la introspección, la entrevista, la observación y la discusión se usan en búsqueda de evidencia. El casuista propone casos reales o ficticios, íntimamente relacionados con problemas reales o con situaciones posibles, $y$, aunque incluso estos puedan sonarnos inverosímiles, la realidad siempre supera a la ficción. El confesionario, donde los pecados son agudamente revisados, y la preocupación por guiar las mentes y los espíritus, tuvieron un papel central en la obtención de información privilegiada disponible para la construcción de casos. 
El confesionario permitió realizar una verdadera anamnesis. El EC también usa ampliamente estos instrumentos, especialmente la entrevista en profundidad tan propia de las etnografías y los casos psicológicos.

- Consideran la utilidad de un caso típico. Un EC típico podría ser extensivo a casos similares, a pesar de que reconozcamos la especificidad, unidad y ageneralización lineal. Un CC típico es asimilable a otros, al menos en la aplicación de principios morales y/o en las normas de reflexión y construcción. Un EC típico trata de buscar regularidades comunes para la interpretación (leyes del caso), en base a que los significados se construyen socialmente, aportando por tanto una mejor comprensión de los casos diferentes.

- Formación de los individuos. La tradición casuística trató de la formación de la conciencia moral en un doble sentido: interiorizar principios, que permitan al individuo decidir sobre una acción inmediata, y dotarles con nuevos instrumentos que guíen la conciencia en acciones futuras. El EC aspira a contribuir a la compresión de cómo las personas hacen uso práctico de lo que han aprendido.

- Comparten una visión optimista de la realidad y una concepción racional del conocimiento. Pese a que podríamos esperar de ambas aproximaciones una actitud de escepticismo epistemológico, dada la complejidad y multidimensionalidad de los fenómenos sometidos a escrutinio; no deja de parecernos paradójico esa compartida visión optimista de la realidad, cuando acometen la acertada tarea de racionalizarla, a la búsqueda de una determinada verdad, no siempre coincidente con la verdad oficial. Lejos de dogmatismo y pretensiones totalistas en la búsqueda de la verdad, CC y EC hacen al conocimiento universal relativo ya que asumen como esencial la particularidad de un hecho específico.

\section{Algunas diferencias básicas para la discusión}

Cuatro diferencias fundamentales podemos señalar entre estas dos aproximaciones; a saber:

- Finalidad. La diferencia básica prima facie entre CC y EC es que el primero es ante todo prescriptivo mientras que el segundo es básicamente descriptivo. Otra distinción significativa, subyace en la función del mediador: directiva en CC y pretendidamente no directiva en EC. Por tanto, el casuista y el investigador por EC realizan diferentes roles a lo largo de su trabajo.

- Dimensión hermenéutica. Las dimensiones hermenéuticas se usan de modo distinto en cada aproximación. La hermenéutica en CC es sólo 
una interpretación sutil de principios morales, los cuales son aplicados después a cada caso preciso, para discernir la moralidad de éste. En EC, la hermenéutica es un arte que permite examinar vívidamente el significado oculto de un caso, sin ninguna referencia a principios generales fijos. Pero si se acepta que toda investigación está dirigida por la teoría, y esa teoría tiene una función crítica y liberadora, ¿no estaríamos, entonces, aceptando realmente un principio moral?

- Fundamentación epistemológica. La base epistemológica en cada aproximación es distinta también. La casuística más ortodoxa usaba la deducción desde el principio al caso, mientras que el EC usa, ante todo, la inducción desde casos para llegar al principio. No obstante, esta divergencia podría estar atenuada para los casuistas heterodoxos (laxistas), para quienes la fuerza de las circunstancias particulares se pondera antes que el rigor de la norma. En este sentido, Tomás de Aquino, en De veritate [Sobre la verdad], declaró: Nullus ligatur per praeceptum aliquod nisi mediante sciencia illius praecepti [Nadie está comprometido con la ley si no es consciente de que ésta existe]. Este principio, que es la base de un probabilismo moderado aún aceptado hoy día por la Iglesia Católica, choca con este otro, aceptado por lo común, de que la ignorancia de la ley no exime de su cumplimiento.

Además, ¿qué es más relevante, resolver casos u obtener principios que sólo pueden ser aplicados a un número limitado de casos? ¿Hay principios aplicables? ¿Cómo podrían aplicarse?

Wundt, en su Etik (1917), al mismo tiempo que establecía la psicología moderna, también alentaba a la aplicación de principios positivistas a las ciencias sociales, a través del estudio de tópicos ético-morales operando inductivamente mediante EC. Wundt estaba altamente preocupado con el estudio de la metodología en fenómenos ético-morales, dedicando nueve páginas de su libro (pp. 21-29) a esta cuestión. Aquí, él destaca que el procedimiento empírico debe preceder al especulativo. Wundt concibe como métodos empíricos aquellos que parten de la experiencia elaborada: la mente opera sobre conceptos que son abstracciones inmediatas e inducciones de la experiencia (p. 29). Al mismo tiempo, reconoce la observación interna y externa como el método más importante para investigar, cuando señala una distinción entre métodos empíricos:

Los métodos empíricos se dividen en dos direcciones: una subjetiva, la cual prefiere las condiciones de nuestras acciones voluntarias presentes en la experiencia interna [reconociendo entonces el valor de la introspección] y otra objetiva, la cual considera los fenómenos dentro de la historia y la sociedad. Ambas direcciones se solapan, son complementarias una de la otra (p. 28). 
Un debate metodológico entre dos aproximaciones al...

Además, él aboga por que: Expertos de cada dirección deben unirse para trabajar juntos en lugar de luchar unos con otros (p. 26).

La crítica de Wundt (1917) al deductivismo corre paralela al método especulativo y a su inferencia: que las leyes morales por origen suprasensible sean un vínculo por el que el ser humano llega a unirse con su eterna fuente primitiva ${ }^{9}$. Nadie puede evadirse del poder de la experiencia. Si alguien quiere eludirla en el camino principal, se la encontrará en los atajos (pp. 23-24).

- Autonomía. El CC no tiene autonomía metodológica, basada en principios libremente aceptados, ya que está subordinado a la Teología Moral. El EC es autónomo, y no subordinado a ciencia alguna. De hecho, en última instancia, el EC adopta la reducción eidética fenomenológica que intenta controlar todo lo subjetivo, cuestiona cualquier teoría y desconsidera la tradición. De aquí su fructífera versatilidad como un método de investigación pluridisciplinal.

\section{Epílogo}

Este artículo revisa una cuestión metodológica al confrontar una antigua acepción del caso, el caso de conciencia, con una de las acepciones actuales, el estudio de caso histórico-humanista. El enfoque de cada aproximación es bastante diferente pero ambas tienen algunas similitudes. Además, el método casuístico, uso de CC, podría recordarnos cuestiones pedagógicas perennes propias del campo de la educación. Relacionar casos con principios tiene significancia filosófica e institucional. Por ejemplo: las áreas de formación de profesores podrían impartirse usando análisis epistémicos de las diferentes aproximaciones al caso. La vida moral en las aulas presenta una batalla dialéctica entre casos y principios. La naturaleza del conocimiento pedagógico (lo particular frente a lo universal) podría invocarse y analizarse. Además, las diversas implementaciones de las innovaciones curriculares podrían verse afectadas; por ejemplo: empezar la instrucción con leyes del caso y después aplicarla a casos particulares o viceversa. Estamos ante el eterno y complejo debate entre métodos de enseñanza inductivos frente a deductivos.

No obstante, este debate metodológico, alguien, podría considerarlo falaz y caduco. Pero en toda disputa sobre métodos de investigación, la asociación, conexión e implicaciones con cuestiones educativas actuales debiera desarrollarse por los propios investigadores, de acuerdo a sus consideraciones. No estamos abogando por el retorno del CC, como méto- 
do de investigación, aunque muchos de los problemas que él trató de resolver aún están pendientes, sino mostrando un debate metodológico inadvertido pero, que estimamos, relevante. Eso es lo que pensamos.

\section{Notas}

1 Nos referimos al diseño pre-experimental, según la notación de Cook y Campbell (1979), dado por la notación XO; donde X: tratamiento y O: observación.

${ }^{2}$ Howe y Eisenhart (1990) proponen esta analogía de la mitología griega para denotar el uso de criterios arbitrarios al evaluar informes de investigación.

3 Sísifo fue condenado eternamente por los dioses a escalar una montaña llevando una pesada piedra. Cerca de la cumbre, perdía la roca que rodaba hasta el pié de la montaña. Así pues, los docentes se asemejan bastante a este carácter mítico. Deben llevar a sus alumnos desde principio a final de curso para la obtención de un grado. Cuando ese grado se ha obtenido, el curso acaba. Nuevos cursos, con nuevos grados, a alcanzar en nuevos alumnos, deben lograrse en cursos siguientes, y así sucesivamente.

4 Según Moore (1956, 1990), desde el siglo XVI, los teólogos morales que usaron el método casuístico o de los casos de conciencia, en oposición a aquellos que usaban los métodos especulativo y positivo, fueron llamados casuistas. Por tanto, casuística es una sección de la Teología Moral centrada en el estudio de CCs.

5 En este sentido, Kohlberg (1981) observó que el razonamiento moral descansa en la concepción de cada individuo y avanza según los años a través de estadios evolutivos estandarizados.

6 Antonio Diana (1585-1663), teólogo casuista italiano.

${ }^{7}$ Los mejores casos de conciencia se retrataban usando el popular hexámetro de Quintiliano: quis (¿quién), quid (¿qué?), ubi (¿dónde?), quibus auxillis (¿con auxilio de quién?), cur (¿por qué?), quomodo (¿cómo?) y quando (¿cuándo?).

8 Mucho más tarde el filósofo español Ortega y Gasset (1984) estableció su postulado: Yo soy yo y mis circunstancias, para realzar la importancia de la circunstancia, vista como el entorno externo e interno en relación con el sujeto, pero que él no puede identificar.

9 Esa primera fuente eterna se identifica en alemán con el término: Urquell.

\section{Bibliografía}

ANDRÉs, J. (1980): Técnicas y prácticas de las relaciones humanas. Bogotá: Instituto Latinoamericano de Pastoral de Juventud

ARriagA, R. de (1962): Disputatione theologicae in priman partem D. Thomae. I. En Historia de las ideas estéticas en España, 2. ${ }^{a}$ Parte, (1896), M. Menéndez y Pelayo (traductor), Cap. III. Reimpresión en Barcelona: Teide. (Original publicado en 1643).

Attisani, A. (1957): Casistica. En Enciclopedia Filosofica (col. 1244). Venize-Rome: Centro di Studi Filosofici di Gallarate.

Bromley, D. B. (1986): The case study method in Psychology and related disciplines. Chichester, UK: Wiley: 


\section{Un debate metodológico entre dos aproximaciones al...}

Bujanda, J. (1960): Quinientos casos de conciencia. Madrid: Razón y Fé. Reimpresión como Casos de conciencia (1963) por E. Olivares.

CAmpbell, D. (1975): Degrees of freedom and the case study. Comparative Political Studies 8(2), 178-193.

Caro Baroja, J. (1981): Los pueblos de España. (Vol. 2). Madrid: Istmo.

CARo BARoja, J. (1985): Las formas complejas de la vida religiosa (Siglos XVI y XVII). Madrid: Sarpe.

CARR, E. J. (1976): What is history? Nueva York: Random House. (Traducción al castellano: ¿Qué es la historia? (1978). Barcelona: Seix Barral).

Coller, X. (2000): Estudio de casos. (Cuadernos metodológicos, n. ${ }^{\circ} 30$ ). Madrid: Centro de Investigaciones Sociológicas.

Cook, T. D. y CAmpBell, D. T. (1979): Quasi-experimentation. Design and analysis issues for field settings. Chicago: Rand McNally.

Dublanchy, E. (1932): Cas de conscience. En Dictionnaire de Théologie catholique, (Vol II/ Segunda Parte), (cols. 1815-1820). París: Letouzey:

Dublanchy, E. (1932): Casuistique. En Dictionaire de Théologie catholique, (Vol. II/ Segunda Parte), (cols. 1859-1877). París: Letouzey:

DURKHeIM, E. (1982): Las formas elementales de la vida religiosa: El sistema totémico en Australia. Madrid: Akal. (Original publicado en 1915)

FERRERES, J. B. (1926): Casus conscientiae, propositi ac soluti ad normam codicis canonici. Barcelona: Subirana.

GADAMER, H. G. (1977): Verdad y método: Fundamentos de una hermenéutica filosófica. Salamanca: Sígueme.

GLASER, B. G. y STRAUSS, A. L. (1967): The discovery of grounded theory. Chicago: Aldine.

GENICOT, E. (1901): Casus conscientiae propositi ac soluti. (2 Vols.). Siete ediciones: 1902, 1906, 1909, 1922, 1925, 1938, 1947. Lovaina: Pollennis et Ceuterick.

GURY, J. P. (1865): Casus conscientiae in praecipuas quaestiones theologiae moralis: G.J. Manz: Regensburg (Ratisbona). Cuatro ediciones hispánicas: 1868, 1873, 1879, 1887. Barcelona: Subirana.

HilgenReiner, K. (1933): Kasuistik. En Lexikon für Theologie und Kirche (Vol. V) (pp. 856-67). Herder: Friburgo.

Howe, K. y EISENHART, M. (1990): Standards for qualitative (and quantitative) research: A prolegomenon. Educational Researcher 19(4), 2-9.

KLEIN, H. E. (Ed.) (2000): Creative interactive teaching: Case method and other techniques. Needham, M. A.: WACRA. (Información adicional: http://www.wacra.org).

KoelHBerg, L. (1981): The philosophy of moral development. San Francisco: Harper \& Row.

LAKATOS, I. (1983): La metodología de los programas de investigación científica. Madrid: Alianza Universidad.

LÓPEZ, U. (1942): Il método e la dottrina morale nei classici de la Compagnia di Gesù. En Compagnia di Gesù e le scienze sacre (pp. 83-113). Roma: Analecta Gregoriana, 29.

LÓPEz-BARAJAs, E. y Montoya, J. M. (Eds.) (1995): El estudio de casos: Fundamentos y metodología. Madrid: UNED.

LuMBreRAS, P. (1960): Casus conscientiae antiqui et recentiores quos solvit et collegit (3 Vols.). Madrid: Studium.

McNaIR, M. P. (Ed.) (1954): The case method at the Harvard Business School. Nueva York: McGraw-Hill.

Merriam, S. (1988): Case study research in education. A qualitative approach. San Francisco: Jossey-Bass. 
Moore, E. (1956): La Moral en el siglo XVI y primera mitad del XVII. Ensayo de síntesis histórica y estudio de algunos autores. Granada: Imprenta de Francisco Román Camacho.

Moore, E. (1990): Los jesuitas en la historia de la Teología Moral. Studia Moralia 28(1), 223-245.

ORTEGA y Gasset, J. (1984): Meditaciones del Quijote Madrid: Cátedra. (Original publicado en 1914).

PASCAL, B. (1966): Les Provinciales (ou lettres écrites par Luois de Montalte à un provincial de ses amis et aux RR.PP. jesuites sur le sujet de la morale et de la politique de ces Pères. Paris: Gallimard et Librerie Générale Française. (Original publicado en 1656-57). (Traducción al castellano como «Las Provinciales». En Obras (1981). Madrid: Alfaguara).

PlatT, J. R. (1964): Strong inference. Science october, 3437-3453.

PÉrez Serrano, G. (1994): Investigación cualitativa. Retos e interrogantes (Vol. I). Madrid: La Muralla.

RAMíREZ, M. S. (1972): Métodos de educación de adultos. Madrid: Marsiega.

RAGIN, C. y BECKER, H. (1992): What is a case? Nueva York: Cambridge University Press.

STAKE, R. E. (1988): Case study methods in educational research. En Complementary Methods for Research in Education, R. M. Jaeger (Ed.) (pp. 253-265). Washington, D.C.: AERA.

STURMAN, A. (1997): Case study methods. En Educational research, methodology, and measurement: An international handbook, J. P. Keeves (Ed.) (2.a ed.) (pp. 61-66). Nueva York: Pergamon.

YIN, R. K. (1989): Case study research: Design and methods (rev. ed.). Newbury Park, CA: Sage.

Toulmin, S. E.; RIEke, R. y JANIK, A. (1979): An introduction to reasoning. Londres: Collier Macmillan.

Wundt, W. (1917): Ética. Una investigación de los hechos y leyes de la vida moral. Madrid: D. Jorro, Editor. (Traducción española de la 4. ${ }^{a}$ edición alemana, 1916). (Original en alemán publicado en 1867). 